\title{
A Simple Method for the Estimation of Protein Retention in Hydrophobic Interaction Chromatography Under Different Operation Conditions
}

\author{
Andrea Mahn ${ }^{*}, 1,2$, M. Elena Lienqueo ${ }^{2}$ and Juan A. Asenjo ${ }^{2}$ \\ ${ }^{I}$ Department of Chemical Engineering, Universidad de Santiago de Chile, Av. Libertador Bernardo O'Higgins 3363, \\ Estación Central, Santiago, Chile \\ ${ }^{2}$ Centre for Biochemical Engineering and Technology, University of Chile, Santiago, Chile
}

\begin{abstract}
Protein behavior in Hydrophobic Interaction Chromatography using different chromatographic conditions was investigated. A linear correlation was found between protein retention time on different matrixes and different initial elution salt concentrations. Mathematical correlations between retention times under different chromatographic conditions were obtained and validated, which can be used in process design and scale-up.
\end{abstract}

Keywords: Hydrophobic interaction chromatography, chromatographic conditions, dimensionless retention time.

\section{INTRODUCTION}

Hydrophobic Interaction Chromatography (HIC) is one of the key techniques used for protein purification and also largely used in industrial operations. In HIC, proteins are induced to bind to a weakly hydrophobic ligand attached to a stationary phase under high salt concentration conditions. Elution is achieved by decreasing the ionic strength in the mobile phase in a linear gradient [1]. This technique shows a similar capacity to Ion Exchange Chromatography and a similar level of resolution.

HIC is widely used in the downstream processing of proteins, and a huge effort has been done in order to elucidate the way the operating conditions affect protein behaviour in HIC [2 -10]. The main system factors that affect protein retention in HIC are concentration and type of salt [2-6] and type of matrix $[2,7,8,11]$, while the main protein property exploited is surface hydrophobicity [12-15]. Many attempts have been carried out to find the relation between protein hydrophobicity, estimated by different methods, and protein retention time in HIC [17-19]. There are also many studies about the way system variables can affect protein retention in HIC [8, 20-22]. Recently it has been shown that the statistically significant system variables are salt properties (measured as molal surface tension increment of the salt $\sigma_{\mathrm{s}}$ ), ionic strength of the initial eluent and substitution degree of the resin (as given by the manufacturer) [23]. Despite the growing knowledge about system and protein characteristics that affect protein behavior in HIC, it would be very useful to elucidate if any relationship exists between protein behavior using different operating conditions.

In this paper the relationship between the chromatographic behavior of proteins under different chromatographic conditions was studied. Our aim was to find simple correlations that could be used to predict a protein's retention time under certain operational conditions with a reduced number of experiments. These relations could probably be

*Address correspondence to this author at the Department of Chemical Engineering, Universidad de Santiago de Chile, Av. Libertador Bernardo O’Higgins 3363, Estación Central, Santiago, Chile; Tel: (56-2) 7181833; Fax: (56-2) 6817135; E-mail: amahnV்2000@yahoo.es useful to refine a purification process and we think they could help to choose the best operating conditions in a purification process design.

\section{MATERIALS AND METHODOLOGY}

Ten well-characterised proteins were used: conalbumin (con), ribonuclease A (rib), ovalbumin (ova), chymotripsinogen A (chy), lysozyme (lys), $\alpha$-lactalbumin (lac), myoglobin (myo), $\alpha$-chymotripsin (chn), concanavalin A (coa), $\alpha$ amylase (amy), from Sigma Chemical Co. (St Louis, Mo, USA). Water, prepared from a Milli-Q water cleaning system (Millipore, Bedford, MA, USA) and analytical-reagent grade ammonium sulphate and sodium chloride was used in the preparation of the elution buffer (buffer B).

The high-performance liquid chromatography system employed consisted of a FPLC (GE Healthcare, Uppsala, Sweden) equipped with a $200-\mu 1$ injection loop. The chromatographic matrixes were Phenyl-Sepharose 6 Fast Flow and Butyl-Sepharose Fast Flow (a gift of GE Healthcare, Uppsala, Sweden) packed in 1-mL columns. The experiments were performed at room temperature, using a flow rate equal to $0.75 \mathrm{ml} / \mathrm{min}$ and a $10 \mathrm{CV}$ decreasing elution gradient. A decreasing salt gradient was used, with a steepness of $7.5 \%$ $\mathrm{B} / \mathrm{min}$ (a $10 \mathrm{CV}$ gradient). The initial eluent was Bis-Tris 20 $\mathrm{mM} \mathrm{pH} 7.0$ plus a maximum salt concentration of 2 or $1 \mathrm{M}$ Ammonium sulphate or 4 or $2 \mathrm{M}$ Sodium chloride (donated by Amersham Pharmacia Biotech, Uppsala, Sweden). The final eluent was Bis-Tris 20-mM pH 7.0 (Buffer A). All buffers were filtered through 0.22-um Millipore filters after preparation and degassed with helium for $10 \mathrm{~min}$. Protein solutions were prepared to contain approximately $0.5 \mathrm{mg} / \mathrm{ml}$ dissolved in the initial eluent. All samples were filtered through $0.22-\mu \mathrm{m}$ Millipore filters.

Different experiments were performed using different combinations of type of matrix (Butyl or Phenyl-Sepharose), salt type (ammonium sulphate or sodium chloride) and initial salt concentration (varying from 1 to $4 \mathrm{M}$ ). The experimental conditions tested were the following: Phenyl-Sepharose-1M Ammonium sulphate, Phenyl-Sepharose-2M Ammonium sulphate, Phenyl-Sepharose-2M Sodium Chloride, PhenylSepharose-4M Sodium Chloride, Butyl-Sepharose-1M Am- 
monium sulphate, Butyl-Sepharose-2M Ammonium sulphate. Retention time of the proteins under the different conditions was related. In order to describe the chromatographic behaviour we used the parameter "Dimensionless Retention Time" (DRT), defined as follows $[11,14]$ :

$$
D R T=\frac{R T-t_{0}}{t_{f}-t_{o}}
$$

where RT is the time corresponding to the peak maximum in the chromatogram, $t_{0}$ is the time corresponding to the start of the elution gradient and $t_{f}$ is the time corresponding to the end of the salt gradient.

\section{RESULTS AND DISCUSSION}

The dimensionless retention times of nine standard proteins on two different matrixes were compared. Fig. 1 shows the relationship between DRT of proteins on ButylSepharose and that on Phenyl-Sepharose with 2Mammonium sulphate in buffer B (beginning of the elution gradient). The linear relationship obtained has a very high correlation level $(r=0.99)$ and shows that there is virtually no difference in the elution order of the proteins when using Butyl or Phenyl Sepharose. Phenyl-Sepharose shows a somewhat stronger hydrophobic interaction between proteins and matrix. Retention times are 9-10\% higher on this matrix. The correlation obtained between DRT in Butyl Sepharose and that obtained in Phenyl Sepharose is given by equation (2). Given the high correlation level obtained, this correlation could be used to predict the DRT of a protein in one matrix starting from that obtained using another one.

DRT $_{\text {Butyl Sepharose }}=1.09 *$ DRT $_{\text {Phenyl Sepharose }}-0.14$

Fig (1). Comparison of the DRT of nine proteins on different matrixes, Butyl and Phenyl Sepharose. Elution was achieved with a decreasing gradient starting with $2 \mathrm{M}$ Ammonium sulphate. DRT $\mathrm{BS}$ $2 \mathrm{M}$ : dimensionless retention time on Butyl Sepharose, DRT ${ }_{\mathrm{PS}-2 \mathrm{M}}$ : dimensionless retention time on Phenyl Sepharose.

The dimensionless retention times (DRT) of the nine standard proteins with different initial concentration of elution salt were investigated. Fig. 2 shows the relationship between DRT using 1M (PS-1M) and 2M (PS-2M) ammonium sulphate on a Phenyl-Sepharose matrix. Fig. 3 gives the salt concentration at the point of elution of the peak maximum. The correlation between DRT (Fig. 2) using ammonium sulphate at two different initial concentrations was almost linear, showing an acceptable correlation level $(r=0.95)$. How- ever two proteins were not retained when $1 \mathrm{M}$ ammonium sulphate was used: ribonuclease $\mathrm{A}$ and myoglobin. This situation can be explained by the low surface hydrophobicity of these proteins [24]. The correlation level between salt concentration at elution (SCE) using different ammonium sulphate initial concentrations (Fig. 3) was high, with $\mathrm{r}=$ 0.98 . The slope of the linear equation obtained was very close to 1.0 (slope $=0.99$ ) and the intercept was close to 0 (intercept $=0.04)$, hence the initial ammonium sulphate concentration only affects the number of proteins retained by the matrix, and not the elution order of proteins nor their retention time.

Fig (2). Comparison of DRT of proteins using ammonium sulphate at different initial concentration: $1 \mathrm{M}$ ammonium sulphate v/s $2 \mathrm{M}$ ammonium sulphate on Phenyl Sepharose matrix.

Fig (3). Salt concentration at elution (SCE) of proteins using ammonium sulphate.

Fig. 4 shows the relationship between DRT with 2M (PS$2 \mathrm{M} \mathrm{NaCl}$ ) and $4 \mathrm{M}$ (PS-4M NaCl) sodium chloride on Phenyl-Sepharose matrix. Fig. 5 gives the salt concentration at elution peak maximum (SCE). For sodium chloride this correlation was also satisfactory, but three proteins retained with $4 \mathrm{M}$ sodium chloride were not retained when using 2 
$\mathrm{M}$ : ribonuclease $\mathrm{A}$, myoglobin and concanavalin $\mathrm{A}$. This indicates that ammonium sulphate promotes a much stronger hydrophobic interaction between proteins and hydrophobic resins than sodium chloride, as can be expected from the Hofmeister's lyotropic series [11]. On the other hand, five proteins showed very similar DRT when using 4M sodium chloride; hence this salt is not a good candidate for enhancing hydrophobic interactions in HIC, as it shows lower selectivity. A certain operating condition shows high selectivity if proteins with different physicochemical properties show different DRTs. In this case, proteins that have different surface hydrophobicity showed similar DRT when $4 \mathrm{M}$ sodium chloride was used.

As well as with different matrixes, the DRT of a protein using a given initial salt concentration can be predicted starting form the knowledge of DRT with another initial salt concentration. The correction factors for initial salt concentration, which are given by equations (3) and (4), could be used in a purification process design, in order to choose the most appropriate operation conditions for the separation of a target protein.

Ammonium sulphate:

$\mathrm{DRT}_{2 \mathrm{M}}=0.60 * \mathrm{DRT}_{1 \mathrm{M}}+0.38$

Sodium chloride:

$\mathrm{DRT}_{4 \mathrm{M}}=0.32 * \mathrm{DRT}_{2 \mathrm{M}}+0.51$ the native structure of proteins in solution, in contrast to the

Fig. (5). Salt concentration at elution (SCE) of proteins using sodium chloride in elusion buffer.

chloride anion, which shows a destabilising effect [4]. Hence ammonium sulphate allows a higher selectivity than sodium chloride in HIC.

Therefore, it would not be possible to correctly estimate DRT using sodium chloride to build the elution gradient, starting from DRT obtained with ammonium sulphate, given the low correlation level observed.

Fig. (6). Comparison of the DRT of nine proteins using different type of salt to build the elution gradient. The matrix used was Phenyl Sepharose.

In order to validate the correlations presented in the previous sections (equations 2 to 4 ), the DRT of a protein not considered in the previous task (ovalbumin) was estimated under different chromatographic conditions, using equations $2-4$. The results are given in Table 1 . The deviation values obtained in all cases were very low, varying from $1.2 \%$ to $3.9 \%$. This indicates that it would be possible to predict a protein's retention time under certain operating conditions starting from the DRT obtained under another conditions. If this result is considered for a purification process design, experimental work could be minimized in choosing the op- 
Table 1. Validation of the Correlations

\begin{tabular}{|c|c|c|c|}
\hline \multicolumn{3}{|c|}{ Operating Conditions } & \multirow[t]{2}{*}{${ }^{\mathrm{e}} \mathbf{D}(\%)$} \\
\hline \multicolumn{3}{|c|}{ Type of Matrix } & \\
\hline${ }^{\mathrm{a}}$ DRT Phenyl Sepharose & ${ }^{\mathrm{a}}$ DRT Butyl Sepharose & ${ }^{\mathrm{b}}$ Predicted DRT ${ }_{\text {Butyl Sepharose }}$ & \\
\hline 0.567 & 0.498 & 0.478 & 3.9 \\
\hline \multicolumn{4}{|c|}{ Ammonium Sulphate initial concentration } \\
\hline${ }^{\mathrm{a}} \mathrm{DRT}_{1 \mathrm{M}}$ & ${ }^{\mathrm{a}} \mathrm{DRT}_{2 \mathrm{M}}$ & ${ }^{\mathrm{c}}$ Predicted DRT $2 \mathrm{M}$ & \\
\hline 0.323 & 0.567 & 0.574 & 1.2 \\
\hline \multicolumn{4}{|c|}{ Sodium Chloride initial concentration } \\
\hline${ }^{\mathrm{a}} \mathrm{DRT}_{2 \mathrm{M}}$ & ${ }^{\mathrm{a}} \mathrm{DRT}_{4 \mathrm{M}}$ & ${ }^{\mathrm{d}}$ Predicted DRT ${ }_{4 \mathrm{M}}$ & \\
\hline 0.724 & 0.756 & 0.742 & 1.9 \\
\hline
\end{tabular}

timal operating conditions for the separation of a target protein.

\section{CONCLUSIONS}

The effect of chromatographic conditions (type of matrix, type and initial concentration of salt) on a proteins' behavior in HIC was studied for Butyl-Sepharose and PhenylSepharose and for ammonium sulphate and sodium chloride. Elution order of proteins was not affected by the type of matrix; retention time is about $10 \%$ higher on PhenylSepharose. Initial salt concentration does not affect the elution order of proteins, showing a good agreement between the DRT obtained with $1 \mathrm{M}$ and $2 \mathrm{M}$ ammonium sulphate or $2 \mathrm{M}$ and $4 \mathrm{M}$ sodium chloride in a linear decreasing gradient. Proteins showed a different behaviour when using a different type of salt. Selectivity was reduced when using sodium chloride, and fewer proteins were retained, hence ammonium sulphate should be preferred as an elution salt.

Simple linear correlations were obtained between DRTs under different chromatographic conditions, which could probably be used in a purification process design, in order to reduce the experimental work. Besides, we believe they could help to choose better operating conditions in an established purification process.

\section{AKNOWLEDGEMENTS}

Fondecyt projects 1061154 and 1030668 supported this research. Pharmacia (Uppsala, Sweden) kindly supplied some resins.

\section{REFERENCES}

[1] Fausnaugh JL, Kennedy LA, Regnier FE. Comparison of hydrophobic-interaction and reversed-phase chromatography of proteins. J Chromatogr 1984; 31: 141-55.

[2] Hjerten S, Rosengren J, Pahlman S. Hydrophobic interaction chromatography. The synthesis and the use of some alkyl and aryl derivatives from agarose. J Chromatogr 1974; 101: 281-8.

[3] Melander W, Horvath Cs. Salt effects on hydrophobic interactions in precipitation and chromatography of proteins: an interpretation of the lyotropic series. Arch Biochem Biophys 1977; 183: 200-15.
[4] Arakawa T, Timasheff SN. Preferential interactions of proteins with salts in concentrated solutions. Biochemistry 1982; 23: 654562.

[5] Melander W, Corradini D, Horváth Cs. Salt-mediated retention of proteins in hydrophobic-interaction chromatography. application of solvophobic theory. J Chromatogr 1984; 317: 67-85.

[6] Fausnaugh JL, Regnier FE. Solute and mobile phase contributions to retention in hydrophobic interaction chromatography of proteins. J. Chromatogr. 1986; 359: 131-46.

[7] Lin FY, Chen WY, Ruaan R-C, Huang H-M. Isothermal titration microcalorimetric studies of the effect of temperature on hydrophobic interaction between proteins and hydrophobic adsorbents. J Colloid Interface Sci. 2000; 229 (2): 600-6.

[8] Machold C, Deinhofer K, Hahn R, Jungbauer A. Hydrophobic interaction chromatography of proteins. I. Comparison of selectivity. J Chromatogr A 2002; 972: 3-19.

[9] Xia F, Nagrath D, Cramer SM. Effect of $\mathrm{pH}$ changes on water release values in hydrophobic interaction chromatographic systems. J Chromatogr A 2005; 1079: 229-35.

[10] Haidacher D, Vailaya A, Horvath Cs. Temperature effects in hydrophobic interaction chromatography. Proc Natl Acad Sci USA 1996; 93: 2290-5.

[11] Jennissen HP. Hydrophobic interaction chromatography: harnessing multivalent protein-surface interactions for purification procedures. Methods Mol Biol 2005; 305: 81-99.

[12] Queiroz JA, Tomaz CT, Cabral JMS. Hydrophobic interaction chromatography of proteins. J Biotechnol 2001; 87: 143-59.

[13] Lienqueo ME, Mahn AV, Asenjo JA. Mathematical correlations for predicting protein retention times in hydrophobic interaction chromatography. J Chromatogr A 2002; 978: 71-79.

[14] Lienqueo ME, Mahn A, Vásquez L, Asenjo JA. Methodology for predicting the separation of proteins by hydrophobic interaction chromatography and its application to a cell extract. J Chromatogr A 2003; 1009: 189-96.

[15] Ladiwala A, Xia F, Luo Q, Breneman CM, Cramer SM. Investigation of protein retention and selectivity in HIC systems using quantitative structure retention relationship models. Biotechnol Bioeng 2006; 93: 836-50.

[16] Katti A, Maa YF, Horvath Cs. Protein surface-area and retention in hydrophobic interaction chromatography. Chromatographia 1987; 24: 646-50.

[17] Melander W, El Rassi Z, Horvath Cs. Interplay of hydrophobic and electrostatic interactions in biopolymer chromatography: effect of salts on the retention of proteins. J Chromatogr 1989; 469:3 -27.

[18] Mahn A, Lienqueo ME, Asenjo JA. Effect of surface hydrophobicity distribution on retention of ribonucleases in hydrophobic interaction chromatography. J Chromatogr A 2004; 1043: 47-55. 
[19] Mahn A, Zapata-Torres G, Asenjo JA. A theory of protein-resin interaction in hydrophobic interaction chromatography. J Chromatogr A 2005; 1066: 81-88

[20] Geng X, Guo L, Chang J. Study of the retention mechanism of proteins in hydrophobic interaction chromatography. J Chromatogr 1990; 507: 1-23.

[21] Xia F, Nagrath D, Garde S, Cramer SM. Evaluation of selectivity changes in HIC systems using a preferential interaction based analysis. Biotechnol Bioeng 2004; 87: 354-63.

Received: March 15, 2007
$[22]$

Perkins TW, Mak DS, Root TW, Lightfoot EN. Protein retention in hydrophobic interaction chromatography: Modeling variation with buffer ionic strength and column hydrophobicity. J Chromatogr A 1997; 766: 1-14.

[23] Mahn A, Lienqueo ME, Asenjo JA. Optimal operation conditions for protein separation in Hydrophobic Interaction Chromatography. J Chromatogr B 2006; doi: 10.1016/j.jchromb.2006.09.013.

[24] Mahn A, Thesis D. University of Chile, (2004).

[25] Hofmeister F. Zur Lehre von der Wirkung der Salze. Arch Exp Path Pharmakol 1888; 24: 247- 60. 